\title{
Preliminary result of randomized trial of an oral thrombolytic agent for deep venous thrombosis, cardiac emboli and carotid atheromatous plaques in patients with infarctive stroke: a report of three (3) cases
}

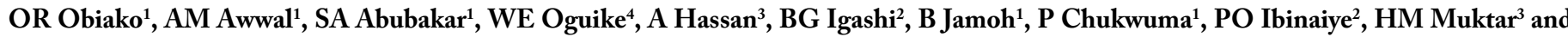 \\ P Azuh $^{1}$ \\ ${ }^{1}$ Neurology/cardiology/clinical haematology/clinical pharmacology units, Department of Medicine, Ahmadu Bello University Teaching Hospital Shika Zaria, Nigeria \\ ${ }^{2}$ Department of Radiology, Ahmadu Bello University Teaching Hospital Shika Zaria, Nigeria \\ ${ }^{3}$ Department of Haematology and Blood Transfusion, Ahmadu Bello University Teaching Hospital Shika Zaria, Nigeria \\ ${ }^{4}$ Stroke Investigation, Research and Education Network (SIREN) Department of Medicine, Ahmadu Bello University Teaching Hospital Shika Zaria, Nigeria
}

\begin{abstract}
Thrombo-embolic conditions, particularly deep venous thrombosis, intramural cardiac thrombi and carotid atheromatous plaques require immediate medical attention because of their propensity to produce fatal pulmonary, cardiac and cerebrovascular outcomes. Treatment of these conditions are varied and sometimes complicated. In this paper, we report successful treatment of each of these three conditions using oral NattoEnzym supplement tablets, with the aim to great awareness of the effectiveness of NattoEnzym in thrombo-embolic conditions.
\end{abstract}

\section{Introduction}

Thrombosis is a term for a blood clot occurring inside a blood vessel, usually the vein more than the artery. A common type of venous thrombosis is a deep vein thrombosis (DVT), which is a blood clot in the deep vein. DVT can occur in any part of the body, but the DVT of the leg is the most common [1]. The symptoms of DVT may include redness, pain, swelling, and warmth of the affected area; although occasionally there may be no symptom (1). Thrombosis can also occur in the superficial veins, but because of the presence of an inflammatory process in its evolution, the pathology is called thrombophlebitis [2], although the treatments for both conditions are similar [3].

The underlying mechanism of thrombosis typically involves the combination of decreased blood flow rate (stasis), increased tendency of blood to clot (hypercoagulable state) and injury to the blood vessel wall (endothelial damage) [4,5].

Risk factors for thrombosis include recent surgery, cancer, obesity, sedentary lifestyle, trauma or bone fractures, cigarette smoking, hormonal birth control, pregnancy, peurperium, antiphospholipid syndrome [6-10], and certain genetic conditions such as deficiencies of antithrombin, protein $\mathrm{C}$ and protein $\mathrm{S}$, and factor $\mathrm{V}$ Leiden mutation $[11,12]$.

The commonest and most important complication of venous thrombosis, particularly DVT, is pulmonary embolism (PE), which occurs when a clot detaches and travels to the right side of heart onto the lungs. Both DVT and PE are serious life-threatening venous thrombo-embolic (VTE) conditions which require immediate medical attention. VTE phenomena are also preventable if people who are at risk of them are identified and proper strategies are adopted [13-15].

The strategies for prevention of VTE include use of blood thinning medications (antiplatelets, fibrinolytic agents) [16], anti-clotting agents (anticoagulants), mechanical devices such as compression stockings or compression devices [17] and thrombolytic agents [18]. Anticoagulants, including injectables such as heparin or low molecular weight (LMW) heparin [19], and direct-acting oral anticoagulants (DOACs) such as apixaban, dabigatran, rivaroxaban, edoxaban [20] and warfarin [21] can be used for a number of months.

Thrombolytics provide more rapid lysis of thrombus than anticoagulants; and are indicated in patients with acute PE with haemodynamic instability because they reduce the thromboembolic burden and resistance in the pulmonary circulation thereby improving pulmonary perfusion as well as right ventricular function [22]. Four types of thrombolytics in clinical use are streptokinase, urokinase and anistreplase and the tissue plasminogen activator (t-PA) [23]. Currently only streptokinase and urokinase are available in Nigeria [18], and they are generally given intravenously as in PE or via catheter as in DVT of the extremities [24]; and to be most effective, it is recommended they are given within $30 \mathrm{~min}$ of presentation to the hospital [23].

*Correspondence to: Obiako OR, Department of Medicine, Ahmadu Bello University Teaching Hospital Shika Zaria, Nigeria, E-mail: orobiako87@gmail.com

Key words: atheromatous plaques, clinical trial, thrombolytic agents, venous thrombo-embolism

Received: June 04, 2019; Accepted: June 11, 2019; Published: June 14, 2019 
Obiako OR (2019) Preliminary result of randomized trial of an oral thrombolytic agent for deep venous thrombosis, cardiac emboli and carotid atheromatous plaques in patients with infarctive stroke: a report of three (3) cases

Recently, an oral thrombolytic agent, called NattoEnzym, which is claimed to effectively dissolve venous thrombi as well as atheromatous plaques [24], was introduced to us. We then set out to conduct a randomized clinical trial of NattoEnzym in our centre in accordance with Guidelines for Good Clinical Practice, and the Declaration of Helsinki [25]. The trial received approval from hospital ethics committees on October 18, 2017; after which the trial commenced and is still ongoing. The overall aim of the study is to compare clinical utility of NattoEnzym capsules to standard of care in terms of stroke prevention, VTE prophylaxis and treatment. The primary endpoint is dissolution of DVT, endocardial thrombus/thrombi or atheromatous plaque at 8 weeks of therapy, while secondary endpoint is efficacy (ease of administration, cost of therapy and number of adverse effects).

\section{Materials and Methods of Clinical Trial}

Inclusion criteria were adults (aged $\geq 18$ years) with CT or MRI confirmed cerebral infarctive stroke complicated by cardiac emboli or carotid atherosclerosis and DVT, diagnosed with trans-thoracic echocardiography and doppler ultrasound respectively. Once enrolled, their baseline clotting profile (prothrombin time (PT), activated plasma thromboplastin time (APTT), international normalized ratio (INR)), and full blood counts (FBC) were performed. Patients with hemorrhagic infarctive stroke, blood dyscrasias, anemia, thrombocytopenia or altered consciousness were excluded.

Patients who met inclusion criteria were randomly assigned to either NattoEzym capsules or to standard of care. NattoEnzym was administered as one capsule at 8 am-10 am and two capsules at $8 \mathrm{pm}-10$ $\mathrm{pm}$. Standard of care comprised: atorvastatin $40 \mathrm{mg}$ daily and vasoprin $150 \mathrm{mg}$ daily (for patients with carotid atherosclerosis), subcutaneous LMW heparin 40mg 12 hourly and warfarin 5-10mg daily (for patients with DVT or cardiac emboli). Clotting profile and FBC were monitored every 24 hours for 72 hours, and then weekly for 8 weeks. Adverse effects and events were also monitored.

We therefore report preliminary observations of outcomes of NattoEnzym on three patients: one with DVT, one with atheromatous plaques and DVT and another with cardiac thrombus. These patients were part of stroke patients involved in an ongoing randomized comparison of NattoEnzyme versus standard of care in our centre.

\section{Case Series}

\section{Case 1}

MS was an 85-year-old man, Hausa muslim from Zaria referred from a private hospital with the diagnosis of acute right infarctive stroke and left lower limb swelling.

He had developed pain, swelling, warmth and discoloration of the left lower limb one week after the ictus. The affected limb had wider circumference of more than $3 \mathrm{~cm}$ than the contralateral limb, and Homan's sign was present (calf muscle tenderness on dorsiflexion of affected limb). Thrombosis of left external iliac, common femoral, superficial femoral and popliteal veins (DVT) with lymphedema of the limb was confirmed by examination of left lower limb vascular system on gray scale and Doppler modes with aid of compression and distal augmentation. He had normal carotid arteries on carotid Doppler ultrasound, but had systemic hypertension and hypertensive heart disease (concentric left ventricular hypertrophy with mild systolic and diastolic dysfunction on echocardiography).

After 6 weeks of NattoEnzym, the left lower limb swelling, and pain reduced and power in the affected muscles improved to BMRC $4 / 5$. Repeat examination of limb vascular system on gray scale and Doppler modes with aid of compression and distal augmentation revealed patent left external iliac, common femoral, superficial femoral and popliteal veins with mild surrounding lymphedema. His full blood count and clotting profile remained within normal limits (Table 1).

\section{Case 2}

$\mathrm{SH}, 80$ years old female was admitted with CT scan confirmed left infarctive stroke and acute right femoro-popliteal venous thrombosis which was confirmed by lower limb Doppler ultrasound. In addition, she had systemic hypertension, hypertensive heart disease (intraventricular septal hypertrophy with mild LV diastolic dysfunction on echocardiography) and left carotid atherosclerosis and stenosis (left common carotid artery IMT $=1.2 \mathrm{~mm}$ ). There was a mobile mixed echogenic atheromatous plaque with irregular surface and thickness of $2.7 \mathrm{~cm}$ in the left carotid bulb with the diameter and area stenosis of $40 \%$ and $50 \%$ respectively. There was an immobile homogeneous calcified plaque with regular/smooth surface in the left internal carotid

Table 1. Blood count and Clotting profile of Case Series (3) (Control test values: prothrombin time $(\mathrm{PT})=13$ seconds; activated plasma thromboplastin time $($ APTT) $=34$ seconds; international normalized ratio $(\mathrm{INR})=1.0$; platelet $(\mathrm{PLT})=100-400 \times 10^{9} / 1$; white blood counts $(\mathrm{WBC})=3.5-10.0 \times 10^{9} / 1$; hemoglobin $\left.(\mathrm{HGB})=11.5-16.5 \mathrm{~g} / \mathrm{dl}\right)$

\begin{tabular}{|c|c|c|c|c|}
\hline Phase & Parameter & Case 1 test value & Case 2 test value & Case 3 test value \\
\hline \multirow{3}{*}{ Baseline } & Prothrombin test & 12 seconds & 9 seconds & 18 \\
\hline & APTT & 36 seconds & 30 seconds & 25 \\
\hline & INR & 1.0 & 0.7 & 1.4 \\
\hline \multirow{3}{*}{1 week } & Prothrombin test & 13 & 12 & 36 \\
\hline & APTT & 32 & 30 & 36 \\
\hline & INR & 1.1 & 0.9 & 3.5 \\
\hline \multirow{3}{*}{8 weeks of NattoEnzym } & Prothrombin test & 15 seconds & 9 & 14 \\
\hline & APTT & 38 seconds & 30 & 24 \\
\hline & INR & 1.20 & .9 & 1.0 \\
\hline \multirow{3}{*}{ Baseline } & PLT $\times 10^{9} / 1$ & 214 & 288 & 218 \\
\hline & WBC $\times 10^{9} / 1$ & 6.6 & 6.9 & 6.0 \\
\hline & HGB $\times \mathrm{g} / \mathrm{dl}$ & 10.6 & 10.4 & 11.0 \\
\hline \multirow{3}{*}{8 weeks of NattoEnzym } & PLT $\times 10^{9} / 1$ & 218 & 347 & 321 \\
\hline & WBC $\times 10^{9} / 1$ & 5.9 & 7.2 & 4.3 \\
\hline & HGB $\times \mathrm{g} / \mathrm{dl}$ & 13.1 & 8.1 & 12.2 \\
\hline
\end{tabular}


Obiako OR (2019) Preliminary result of randomized trial of an oral thrombolytic agent for deep venous thrombosis, cardiac emboli and carotid atheromatous plaques in patients with infarctive stroke: a report of three (3) cases

artery with the diameter and area stenosis of $60 \%$ and $70 \%$ respectively, with incomplete filling of artery and absence of diastolic flow proximal to the area of stenosis. However, the right common and internal carotid arteries showed normal IMT, normal arterial spectral waveforms and no plaque.

At 6 weeks of NattoEnzym, repeat lower limb Doppler revealed complete resolution of DVT; while carotid Doppler revealed some resolution of left carotid atherosclerosis (patent left common carotid artery with borderline IMT $=1.0 \mathrm{~mm}$, normal spectral display, no plaque or wall calcification). There was a suggestion of plaque measuring about $3.2 \mathrm{~mm}$ in the left internal artery, but no significant hemodynamic changes were noted. The right internal carotid artery was normal. Her full blood count and clotting profile remained within normal limits (Table 1)

\section{Case 3}

BS, a 50-year-old housewife admitted with CT scan confirmed left infarctive stroke, right hemiplegia and expressive aphasia. Risk factors were systemic hypertension, and hypertensive heart disease (dilated cardiomyopathy with severe systolic and diastolic dysfunctions on echocardiography). There was a left ventricular apical thrombus measuring $8.5 \mathrm{~mm}$ with left ventricular and atrial spontaneous contrast. Her carotids were of normal calibre. On the basis of above findings, a diagnosis of cardio-embolic stroke was made. She was given NattoEnzym and on the $7^{\text {th }}$ day of NattoEnzym, she started spotting blood per anus. Her PT rose from 18 seconds to 36 seconds, APTT from 25 seconds to 36 seconds and INR rose from 1.4 to 3.5 respectively (Table 1). The drug was stopped, and she received one pint of fresh whole blood, and the bleeding stopped spontaneously. Repeat echocardiography was done and it revealed dilated cardiomyopathy with severe systolic and diastolic dysfunctions, but no thrombus (Figures 1 and 2). Repeat clotting profile was also within normal limits (Table 1).

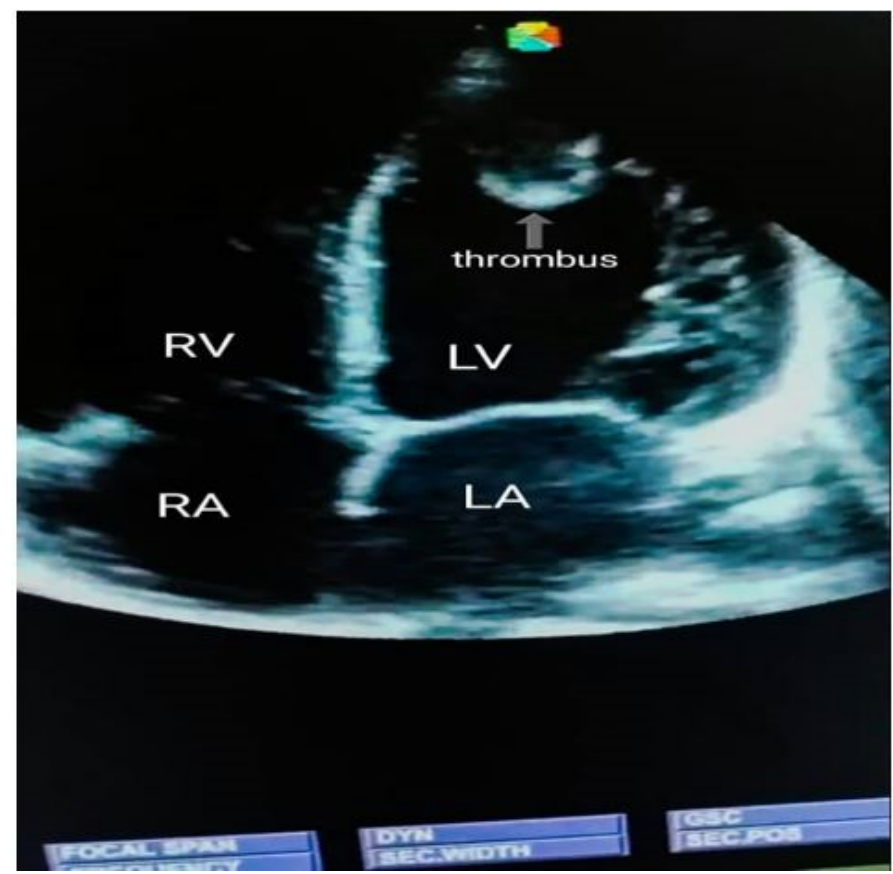

Figure 1. Echocardiography showing no thrombus

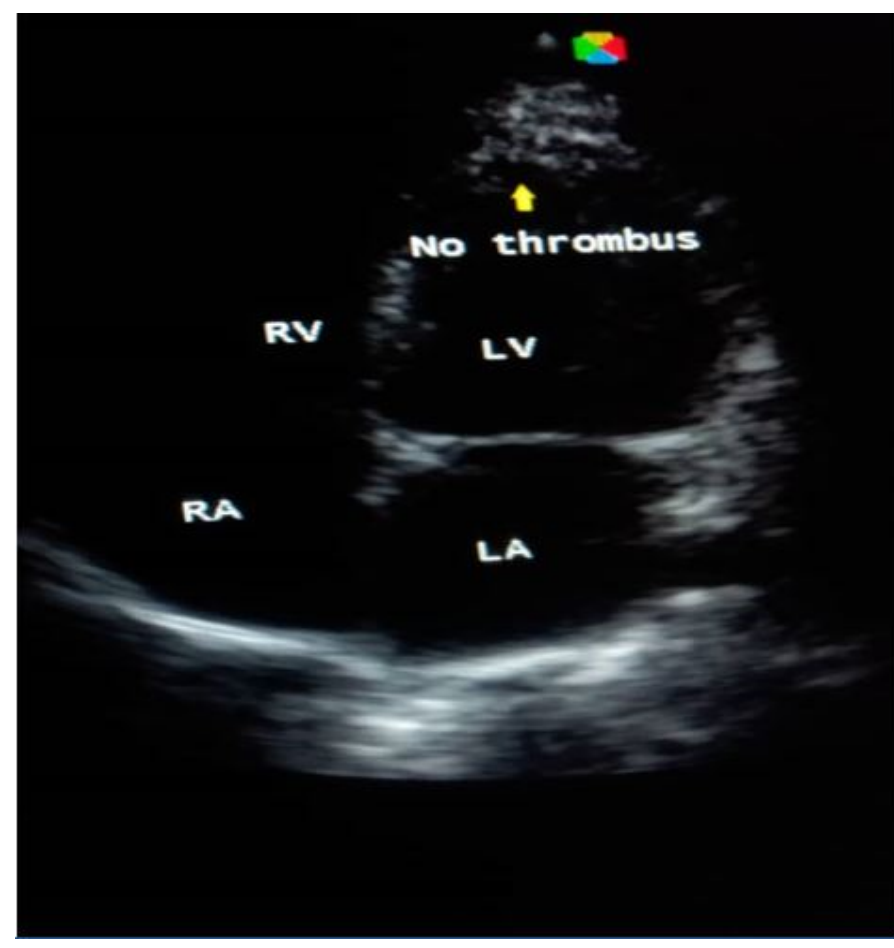

Figure 2. Echocardiography showing no thrombus

\section{Discussion}

NattoEnzym is a constituent of nattokinase, a serine proteolytic enzyme that degrades plasminogen activator inhibitor type 1 (PAI-1) thereby enhancing the production of tissue-type plasminogen activator (t-PA) [26]. The circadian rhythm of PAI-1 shows that it is highest at dawn ( $3 \mathrm{am}-5 \mathrm{am})$ and decreases at time goes on becoming lowest at dusk (5 pm-7 pm) [27]; thus thrombus generation and incidence of cerebral and cardiac infarctions are more likely in the morning (5 am$11.59 \mathrm{am}$ ) [27-28]. The dosage rule of 1:2 (one capsule in the morning and 2 capsules in the night) of NattoEnzym is to enhance its antithrombotic activity in the morning.

NattoEnzym has a half-life of $8-12$ hours, and is effective within 4 hours of oral administration, and reaches peak serum levels in approximately 13 hours. Kinetic assays also suggest that nattokinase is 6 times more active than plasmin in degrading cross-linked fibrin directly. It was found to break down thrombi by directly cleaving the bonds of the fibrin protein components and also by hastening the production of the body's own fibrin buster (plasmin) [26]. Nattokinase also inhibits both the collagen and thrombi induced platelet aggregations, thereby not only inhibiting blood clotting triggered by thrombin, but also blocks TXA2-mediated adhesion of platelets to the injured vessel walls $[29,30]$. It thus breaks down the adhesive substance that makes arterial plaque very sticky, reverses blood clotting and prevents plaque formation in the arteries [30]. Nattokinase has long being used in Japan and South Korea for both primary and secondary prevention of heart attack and stroke because of its safety and minimal side effect [31-33].

\section{Conclusion}

Our preliminary observations (dissolution of thrombi in cases 1,2 and 3 and near resolution of atheromatous plaque in case 2 ), suggest that the drug may be useful as an oral antithrombin, 
Obiako OR (2019) Preliminary result of randomized trial of an oral thrombolytic agent for deep venous thrombosis, cardiac emboli and carotid atheromatous plaques in patients with infarctive stroke: a report of three (3) cases

antiplatelet aggregation and anti -atheroma/ atherosclerotic agent in our environment. However, the rapid increase of INR and subsequent bleeding per anus that occurred in case 3 shows that the drug is not without side effects.

\section{Recommendation}

We recommend a multi-centered and multi-disciplinary randomized clinical trial of NattoEnzym involving more hospitals and more patients in Nigeria.

\section{References}

1. Martinelli I, Bucciarelli P, Mannucci PM (2010) Thrombotic risk factors: basic pathophysiology. Crit Care Med 38: S3-S9. [Crossref]

2. Di Nisio Marcello, Middeldorp S (2014) Treatment of Lower Extremity Superficial Thrombophlebitis. JAMA 311: 729-730. [Crossref]

3. Robertson L, Jones LE (2017) Fixed dose subcutaneous low molecular weigh heparins versus adjusted dose unfractionated heparin for the initial treatment of venous thromboembolism. Cochrane Database Syst Rev 2: CD001100. [Crossref]

4. López JA, Chen J (2009) Pathophysiology of venous thrombosis. Thromb Res 123: S30-S34. [Crossref]

5. Saha P, Humphries J, Modarai B (2011) Leukocytes and the natural history of deep vein thrombosis: Current concepts and future directions. Arterioscler Thromb Vasc Biol 31: 506-512. [Crossref]

6. Goldhaber SZ (2010) Risk Factors for Venous Thromboembolism. J Am Coll Cardiol 56: 1-7. [Crossref]

7. Lijfering WM, Rosendaal FR, Cannegieter SC (2010) Risk factors for venous thrombosis - current understanding from an epidemiological point of view. $\mathrm{Br} J$ Haematol 149: 824-833. [Crossref]

8. Reitsma PH, Versteeg HH, Middeldorp S (2012) Mechanistic view of risk factors for venous thromboembolism. Arterioscler Thromb Vasc Biol 32: 563-568. [Crossref]

9. Stein PD, Beemath A, Meyers FA (2006) Incidence of venous thromboembolism in patients hospitalized with cancer. Am J Med 119: 60-68. [Crossref]

10. Tang L, Wu YY, Lip GY, Yin P, Hu Y (2016) Heart failure and risk of venous thromboembolism: a systematic review and meta-analysis. Lancet Haematol 3: e30-e44. [Crossref]

11. Rosendaal FR (2005) Venous thrombosis: the role of genes, environment, and behavior. Hematology Am Soc Hematol Educ Program 2005: 1-12. [Crossref]

12. Rosendaal FR, Reitsma PH (2009) Genetics of venous thrombosis. J Thromb Haemost 7: 301-304. [Crossref]

13. Lederle FA, Zylla D, Macdonald R, Wilt TJ (2011) Venous thromboembolism prophylaxis in hospitalized medical patients and those with stroke: a background review for an American College of Physicians clinical practice guideline. Ann Intern Med 155: 602-615. [Crossref]

14. Qaseem A, Chou R, Humphrey LL, Starkey M, Shekelle P (2011) Venous thromboembolism prophylaxis in hospitalized patients: a clinical practice guideline from the American College of Physicians. Ann Intern Med 155: 625-632. [Crossref]

15. https://www.ncbi.nlm.nih.gov/pubmed/23346611

16. Simes J, Becattini C, Agnelli G, Eikelboom JW, Kirby AC, et al. (2014) "Aspirin for the prevention of recurrent venous thromboembolism: the INSPIRE collaboration". Circulation 130: 1062-1071. [Crossref]
17. Roderick P, Ferris G, Wilson K, Halls H, Jackson D, et al. (2005) Towards evidencebased guidelines for the prevention of venous thromboembolism: systematic reviews of mechanical methods, oral anticoagulation, dextran and regional anaesthesia as thromboprophylaxis. Health Technol Assess 9: 1-78. [Crossref]

18. Awodu OA, Shokunbi WA, Akanmu AS, Ogbe OP, Bolarinwa R, et al. (2016) Nigerian Society for Haematology and Blood Transfusion. Guideline for management of venous thromboembolism in Nigeria.

19. Alikhan R, Bedenis R, Cohen AT (2014) Heparin for the prevention of venous thromboembolism in acutely ill medical patients (excluding stroke and myocardial infarction). Cochrane Database Syst Rev 5: CD003747. [Crossref]

20. van der Hulle T, Kooiman J, den Exter PL, Dekkers OM, Klok FA, et al. (2014) Effectiveness and safety of novel oral anticoagulants as compared with vitamin $\mathrm{K}$ antagonists in the treatment of acute symptomatic venous thromboembolism: a systematic review and meta-analysis. J Thromb Haemost 12: 320-328. [Crossref]

21. Witt DM, Clark NP, Kaatz S, Schnurr T, Ansell JE (2016) Guidance for the practical management of warfarin therapy in the treatment of venous thromboembolism. $J$ Thromb Thrombolysis 41: 187-205. [Crossref]

22. Blech S, Ebner T, Ludwig-Schwellinger E, Stangier J, Roth W (2008) The metabolism and disposition of the oral direct thrombin inhibitor, dabigatran, in humans. Drug Metab Dispos Biol Fate Chem 36: 386-399. [Crossref]

23. Vedantham S, Piazza G, Sista AK, Goldenberg NA (2016) Guidance for the use of thrombolytic therapy for the treatment of venous thromboembolism. $J$ Thromb Thrombolysis 41: 68-80. [Crossref]

24. Cho YH, Song JY, Kim KM, Kim MK, Lee IY, et al. (2010) NattoEnzym dissolves blood cloth without inhibiting wound healing. Angiology 54: 531-539.

25. https://apps.who.int/medicinedocs/en/d/Jwhozip13e/

26. Sumi H, Hamada H, Nakanishi K, Hiratani H (1990) Enhancement of the fibrinolytic activity in plasma by oral administration of nattokinase. Acta Haematol 84: 139-143. [Crossref]

27. Angleton P, Chander ML, Schner G (1989) Diurnal variations of tissue- type plasminogen activator and its rapid inhibitor (PAI-1). Circulation 79: 101-106. [Crossref]

28. Andreotti F, Davies GT, Hackett DR, Khan MI, De Bart AC, et al. (1998) Major circadian fluctuation in fibrinolytic factors and possible relevance to time of onset of myocardial infarction, sudden cardiac death and stroke. Am J Cardiol 62: 635-637. [Crossref]

29. Fujita M, Nomura K, Hong K, Ito Y, Asada A, et al. (1995) Thrombolytic effect of NattoEnzym on a chemically induced thrombosis model in rat. Biol Pharm Bull 18 : 1387-1391. [Crossref]

30. Pais E, Alexy T, Halsworth RE, Meiseiman HJ (2006) Effect of NattoEnzym, a profibrinolytic enzyme, on red blood cell aggregation and whole blood viscosity. Clin Hemorheol Microcirc 35: 139-142. [Crossref]

31. Sumi H, Hamada H, Tsushima H, Mihara H, Muraki H (1987) "A novel fibrinolytic enzyme (nattokinase) in the vegetable cheese Natto; a typical and popular soybean food in the Japanese diet". Experientia 43: 1110-1111. [Crossref]

32. Fujita M, Nomura K, Hong K, Ito Y, Asada A, et al. (1993) "Purification and Characterization of a Strong Fibrinolytic Enzyme (Nattokinase) in the Vegetable Cheese Natto, a Popular Soybean Fermented Food in Japan". Biochem Biophys Res Commun 197: 1340-1347. [Crossref]

33. Ero M and Lewis B (2008) A randomized controlled trial on the coagulation profile of NattoEnzym, Machaon Diagnostic. Hypertension Res 27: 341-346.

Copyright: (C2019 Obiako OR. This is an open-access article distributed under the terms of the Creative Commons Attribution License, which permits unrestricted use, distribution, and reproduction in any medium, provided the original author and source are credited. 